\title{
Influence of Different Types of Metakaolin on Compressive Strength and Chloride Migration of Concrete
}

\author{
Rodrigo Teodoro ${ }^{1}$, Helena Carasek $^{2}$ and Oswaldo Cascudo ${ }^{3}$ \\ ${ }^{1}$ Laboratory of Technological Innovation in Civil Construction (LABITECC), Federal University of \\ Goias (UFG), Goiania, Brasil, rodrigoteodoro.eng@gmail.com \\ ${ }^{2}$ Laboratory of Technological Innovation in Civil Construction (LABITECC), Federal University of \\ Goias (UFG), Goiania, Brasil, hcarasek@ufg.br \\ ${ }^{3}$ Laboratory of Technological Innovation in Civil Construction (LABITECC), Federal University of \\ Goias (UFG), Goiania, Brasil, ocascudo@ufg.br
}

\begin{abstract}
The use of mineral admixtures in concrete has grown in recent years, specially the highperformance ones, such as silica fume, nanosilica and metakaolin. Metakaolin has been extensively studied due to its high reactiveness. Thus, an experimental program was conducted to evaluate the behavior of compressive strength and non-steady state chloride migration due to differences of metakaolin characteristics. Three different metakaolins were characterized, then used in a $10 \%$ replacement ratio (of mass of cement), among two water/binder ratios (0.40 and 0.60$)$ in concrete mixes. The results show that metakaolin increased compressive strength in every age tested. Moreover, durability properties were significantly enhanced due to the addition of metakaolin. Nonsteady state chloride migration coefficient of metakaolin concretes were noticeably lower than plain concrete. In general, the addition of metakaolin in concrete caused pore refinement and reduction in total porosity, which lead to enhancements of mechanical e durability properties of concrete.
\end{abstract}

Keywords: Durability, Chloride Migration, Metakaolin, Compressive Strength.

\section{Introduction}

Metakaolin (MK) is a relatively new supplementary cementing material (SCM), although there are studies and research in the past century, it was in the last two decades that MK was broadly studied. In Federal University of Goias (UFG), in Brazil, since 2000's several experiments were conducted with MK and other pozzolans (Cascudo, Mendes, Carasek, and Ferreira, 2014; Ferreira, Pereira, Lopes, Carasek, and Cascudo, 2004; Figueiredo et al., 2014; Oliveira and Cascudo, 2018; Pereira, Lopes, Hasparyk, Carasek, and Cascudo, 2005). The results of these researches suggest that the overall good performance of highly reactivity metakaolin owes mainly to its fineness which leads to an enhancement of filler effect on concrete microstructure.

On the other hand, MK is obtained from the calcination of kaolinitic clay, mainly composed of kaolinite (hydrated aluminosilicate), which means that it's major composition is alumina (Khatib, Baalbaki, and ElKordi, 2018; Murat and Comel, 1983; Siddique and Khan, 2011). In this sense, some studies observed that MK can react with chloride ions in concrete resulting in a stable compound knows as Friedel's salt (Friedel, 1897). This means that the addition of metakaolin in concrete can improve the chloride resistance (Cascudo et al., 2014; Talero, 2012), therefore improve the durability of concrete. 
Thus, a research conducted to verify the influence of physical, chemical and mineralogical characteristics of highly reactivity metakaolins in mechanical and durability related properties of concrete. In the present paper the changes in compressive strength and chloride migration caused by MK properties were assessed.

\section{Experimental Program}

This paper is a part of a broader experimental program in which the influence of different types of highly reactivity metakaolins in the microstructure of concrete is evaluated.

\subsection{Materials}

Eight different types of concrete were mixed: with two water/binder ratios $-0,40$ and $0,60-$ as well as three different metakaolins - MK1, MK2 and MK3 - all from the same Brazilian manufacturer in a $10 \%$ content in substation of cement, in mass, and a plain concrete - with no MK - R. The complete composition of all eight mixes is presented in table 1.

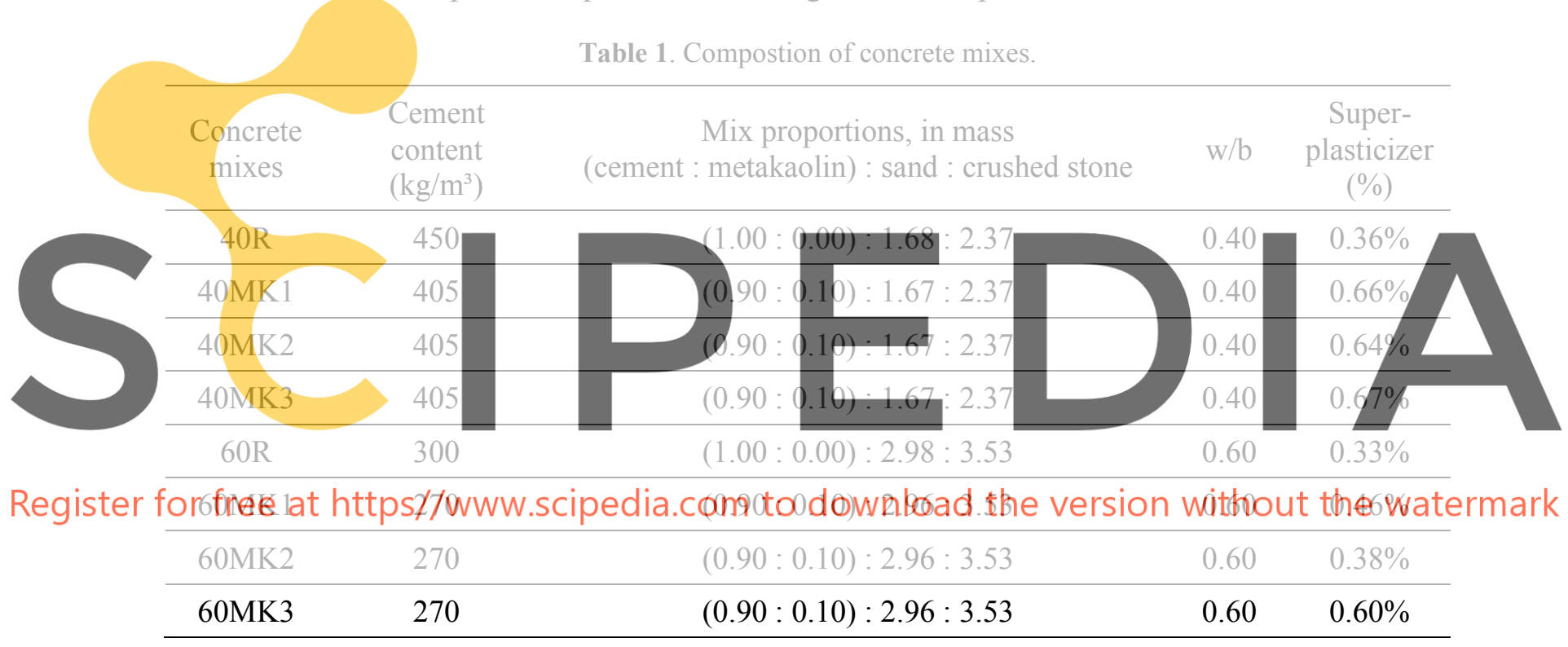

Once the characteristics of the metakaolins are relevant to further understand the possible changes in concrete, some of their physical, chemical and mineralogical properties were analyzed: BET fineness, chemical composition by X-ray fluorescence, quantification of crystalline phases by X-ray diffractometry. Among of them, the pozzolanic index of metakaolin was measured by the Chapèlle's modified test (ABNT, 2010).

An ordinary Portland cement (OPC) (Brazilian type CP II F 40, similar to CEM II/A-L 42.5) was used in all concrete mixtures.

There were also used two different fine aggregates - both quartz sand, one with a fineness modulus of 2.09 and the other one with a MF $=3.54$ - and two different coarse aggregates both gneiss crushed stone, one with a MF equals to 5.71 and the other one with $\mathrm{MF}=6.80$. Also, a polycarboxylate-based superplasticizer was used in order to maintain the slump in a constant range, without changing the $\mathrm{w} / \mathrm{b}$ ratio. 


\subsection{Methods}

Concretes were tested in fresh state in which slump test was conducted to be kept in the range that was proposed $(120 \pm 20 \mathrm{~mm})$. Then cylinder specimens were molded for tests in hardened state. Then they were cured immersed in water saturated of calcium hydroxide, at $(23 \pm 2)^{\circ} \mathrm{C}$ until the age of 28 days. Compressive strength tests were conducted with cylinder specimens $(100 \times 200 \mathrm{~mm})$ of every concrete mix in four ages: 7, 28, 91 and 140 days.

The chloride resistance was measured by the Nordtest method, described in NT Build 492 (Nordtest, 1999). $100 \mathrm{~mm} \times 50 \mathrm{~mm}$ cylindrical specimens were cut from the middle of 100 $\mathrm{mm} \times 200 \mathrm{~mm}$ cylinders; subsequently, the apparatus, as described in the method, was assembled. This method, that was primarily proposed by Tang and Nilsson (1993), consists in forcing the chloride ions to migrate, with a direct electrical current applied in both cathodic and anodic solutions in which a specimen is immersed. This test, after some calculations based in some equations provided by the Nordtest standard, results in a coefficient of migration of chlorides in a non-steady state. This coefficient of migration is close to the coefficient of diffusion, which is the real mass transport of ions that occurs in concrete.

The results were also submitted the statiscal analysis of variance (ANOVA) and multiple mean comparison, from which some charts are presented herein.

\section{Results and Discussion}

Once the results of metakaolins characteristics are relevant to explain the changes in the properties of concrete, the results are presented in two section: first the metakablin results and then the concrete results

3.1 Metakaolims Characterization Although the metakadins are produced by the

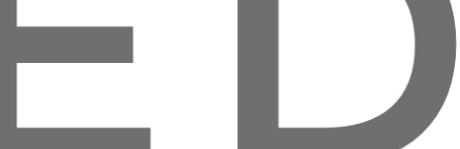

can be seen in their chemical composition, presented in table 2.

Register for free at https//www.scipedia.com to download the version without the watermark Table 2. Chemical compostion of metakaolins.

\begin{tabular}{|c|c|c|c|c|}
\hline Test Method & Content & MK1 & МK2 & MK3 \\
\hline \multirow{9}{*}{$\begin{array}{l}\text { X-ray Fluorescence } \\
\text { Spectroscopy }\end{array}$} & $\mathrm{SiO}_{2}(\%)$ & 56.46 & 52.58 & 51.43 \\
\hline & $\mathrm{Al}_{2} \mathrm{O}_{3}(\%)$ & 32.17 & 44.61 & 42.53 \\
\hline & $\mathrm{Fe}_{2} \mathrm{O}_{3}(\%)$ & 2.23 & 0.35 & 2.00 \\
\hline & $\mathrm{CaO}(\%)$ & 0.17 & 0.06 & 0.16 \\
\hline & $\mathrm{MgO}(\%)$ & 0.7 & 0.02 & 0.28 \\
\hline & $\mathrm{K}_{2} \mathrm{O}(\%)$ & 2.16 & 0.09 & 0.95 \\
\hline & $\mathrm{Na}_{2} \mathrm{O}(\%)$ & 0.04 & 0.04 & 0.02 \\
\hline & L.O.I. (\%) & 4.27 & 1.95 & 1.28 \\
\hline & Others $(\%)$ & 1.65 & 0.11 & 1.14 \\
\hline
\end{tabular}


It is known that MK1 and MK3 are obtained from the same raw material, while MK2 comes from another deposit. MK2 is white, so it is expected that it is the purest of all three, verified by chemical analysis, with around $97 \%$ of silica+alumina. The differences between MK1 and MK2 are also expressive, which may be due from the difference in the processing of raw material in the deposit (mainly a better refinement of the kaolin).

Table 3 shows other properties of metakaolins. The differences in their fineness are relevant. Although MK2 is the purest, it is the coarser metakaolin, which in theory may lead to lower reactivity. Also, it is interesting to observe the difference between the amorphous content, mainly between MK1 and MK3, which can be also explained by differences in the processing of material, especially in the calcination process.

Table 3. Physical and mineralogical properties of metakaolins.

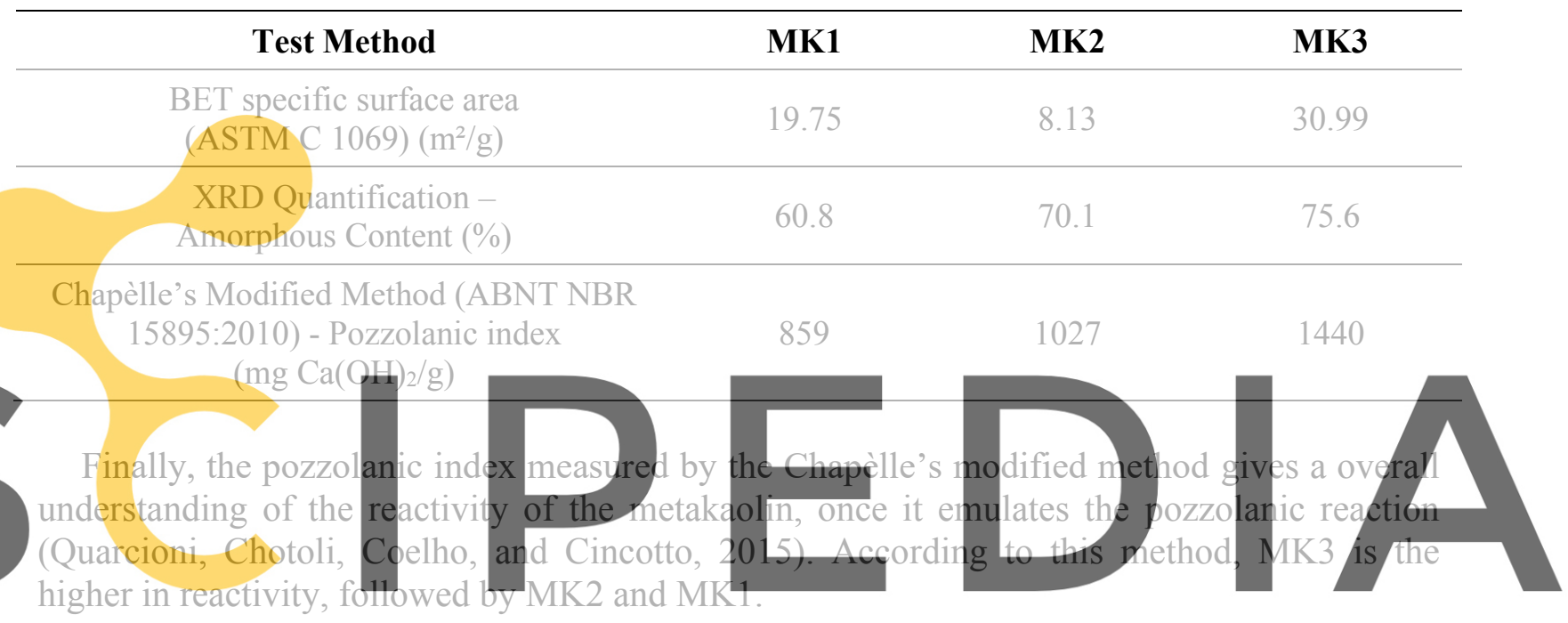

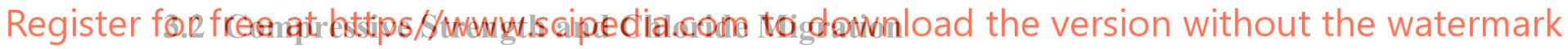

Results of compressive strength along the age of concrete are presented in figure 1.

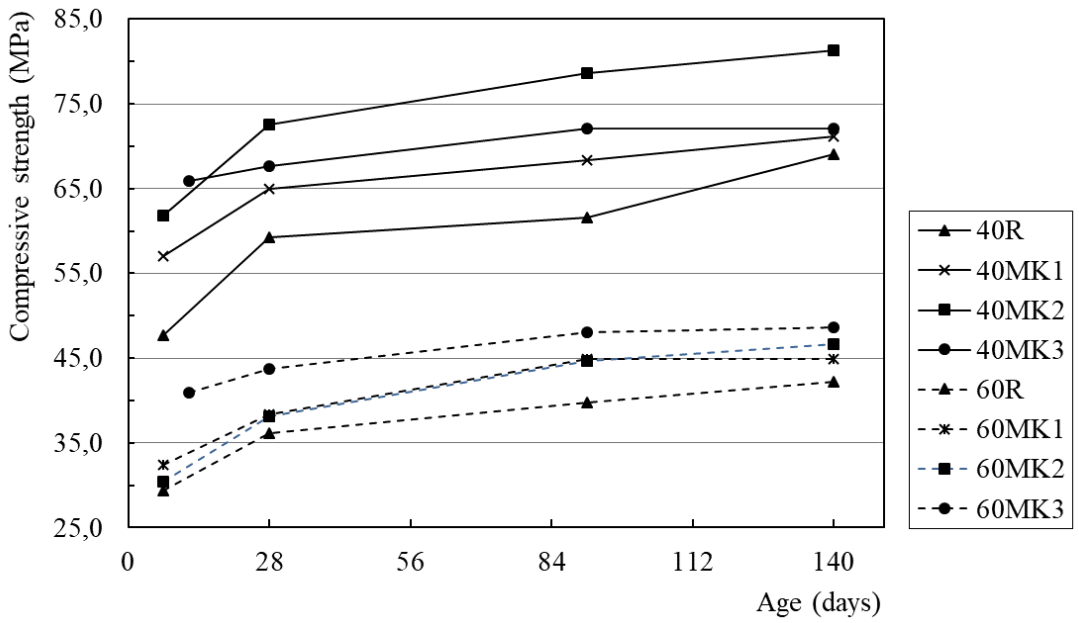

Figure 1. Results of compressive strength of concrete at ages of 7, 28, 91 and 140 days. 
The difference between the $\mathrm{w} / \mathrm{b}$ ratio is noticeable, as expected. It can be also seen that even in early ages MK concrete showed better results, which may be explained by the filler effect that is instantaneous. Also, at later ages MK concretes still showed better results. At 91 days a great part of the pozzolanic reactions have already occurred, it can be observed that mechanisms of action of MK in concrete changes depending on the $\mathrm{w} / \mathrm{b}$ ratio. For the 0.60 concretes, MK3 presented the highest results, though for the 0.40 concretes, MK2 showed the higher value. This can be explained by the differences in the pore structure of the two groups of concrete, as the 0.40 concretes tends to be less porous, the filler effect is not that important compared to those of $\mathrm{w} / \mathrm{b}$ of 0.60 , so the coarser $\mathrm{MK}$, although purer, showed better results, meaning that in this case the chemical reactivity took place.

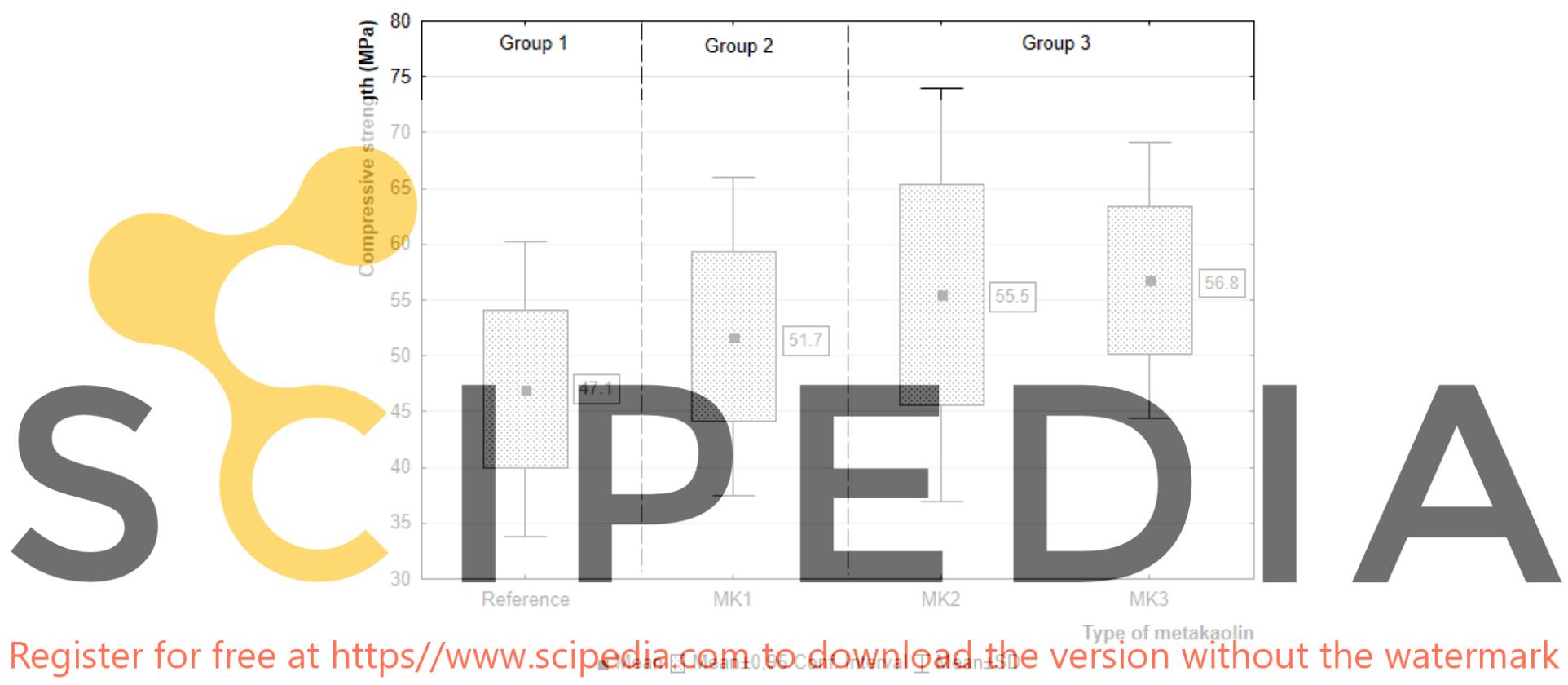

Figure 2. Multiple mean comparison of compressive strength and type of metakaolin.

Analyzing the ANOVA results, it showed that both variables (w/b and type of metakaolin) and their interaction were significant to explain the changes in compressive strength. The coefficient of determination of the model is 0.99. Figure 2 shows the multiple mean comparison segregation of the groups of statically equivalent concretes. It can be concluded that both MK2 and MK3 performed very well, in comparison to MK1 and plain concrete.

In chloride migration tests, MK concretes significantly outperformed plain concretes. Figure 3 shows the results of the non-steady state chloride migration coefficient. The $\mathrm{w} / \mathrm{b}$ ratio was significant in the ANOVA model, as expected. So it was the type of metakaolin and their interaction, resulting in a $\mathrm{R}^{2}$ equals to 0.98 . Different that compressive strength, the Tukey's test from multiple mean comparison segregated the groups of statically equivalent results with some intersection. This means that it is possible to assure that the MK3 is superior than MK1 and plain concrete, but statically equivalent to MK2. 


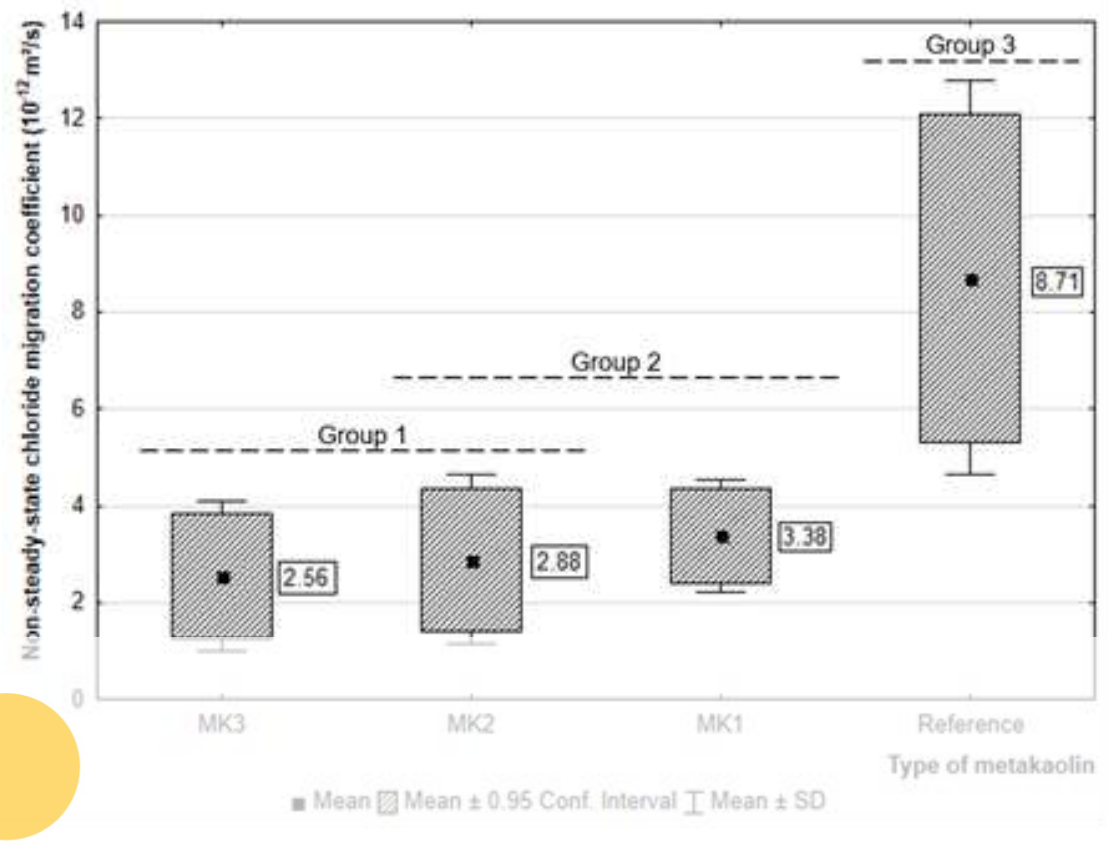

Figure 3. Multiple mean comparison of chloride migration coefficient and type of metakaolin.

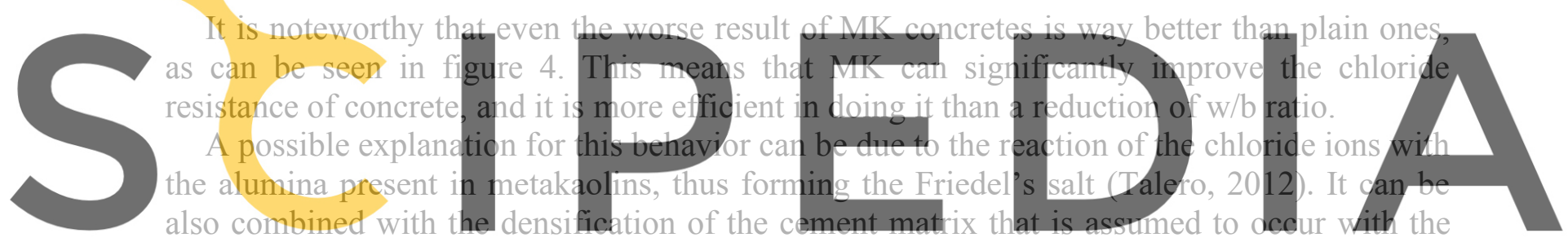
addition of MK, once the compressive strength was also improved.

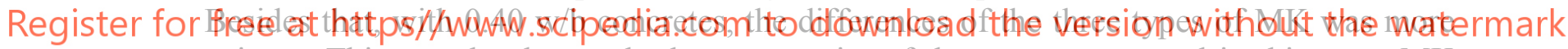
prominent. This may be due to the lower porosity of these concretes, and in this case, MK benefits are more evident, surpassing the effects of $\mathrm{w} / \mathrm{b}$ ratio itself. Besides this, the correlation of these results and the results of Chapèlle's pozolanic index of the metakaolins are higher. This leads to the theory of chemical combination of aluminous phases with chloride ions.

Another interesting point is that every MK concrete is classified, according to Nilsson, Ngo and Gjørv (1998), as a very high or extremely high resistance to chloride attack. This means that MK concretes are significantly more durable than plain concrete. Plain concrete with $\mathrm{w} / \mathrm{b}$ of 0.60 , for example, is classified as a moderate chloride resistance.

It is clear that metakaolin concretes showed better results in comparison to plain concretes. The addition of $\mathrm{MK}$ in concrete seems to be more effective in improving the chloride resistance than the $\mathrm{w} / \mathrm{b}$ ratio, evidenced by the fact that concrete with a higher $\mathrm{w} / \mathrm{b}$ ratio and with the worser MK showed better results than a concrete with lower w/b ratio and without MK.

Also, for the compressive strength the enhancements caused by MK are noticeable, but in this case $\mathrm{w} / \mathrm{b}$ ratio seems to be more relevant to determine. 


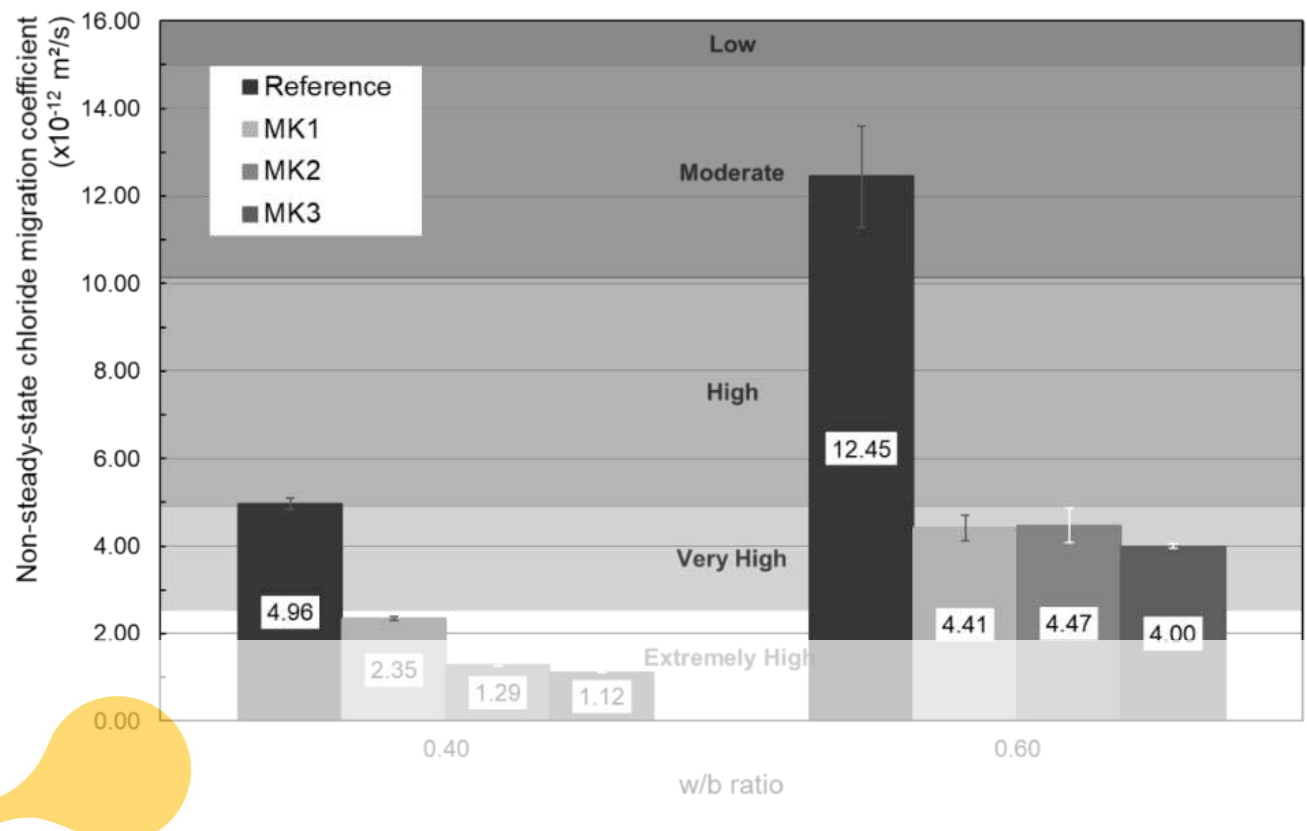

Figure 4. Mean values and standard deviation of non-steady-state chloride migration coefficient of all concrete mixtures, and the classification of chloride resistance from Nilsson, Ngo and Gjørv (1998).

\section{Conclusions}

The pozzolanic activity be accurate to chemical and min

- Compressive strength was improved by the
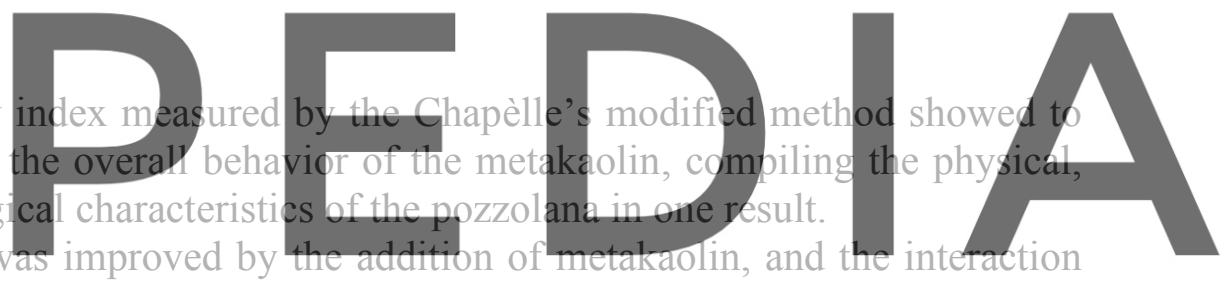

of the SCM was different depending on the w/b ratio.

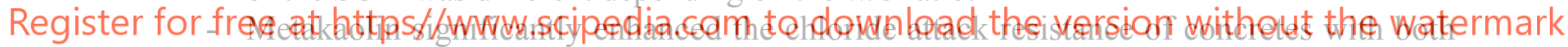

$\mathrm{w} / \mathrm{b}$ ratio, even the worst MK with the $0.60 \mathrm{w} / \mathrm{b}$ presented better result than the 0.40

plain concrete, which demonstrate the effectiveness of MK to prevent chloride attack.

\section{Acknowledgements}

The authors acknowledge the contribution of Metacaulim do Brasil Company, which donated material, supported and financed this research. They also thank the company Eletrobras Furnas for all the support given in the experiments, as well as the following laboratories: LEDMa/UFBA for the XRD tests, LABMIC/UFG for the SEM analysis. Finally, the authors would like to thank CAPES and CNPq (Brazilian governmental institutions), which provided grants to researchers, as well as UFG and PPG-GECON.

\section{ORCID}

Rodrigo Teodoro: http://orcid.org/0000-0002-7302-456X

Helena Carasek: http://orcid.org/0000-0002-1170-0980

Oswaldo Cascudo: http://orcid.org/0000-0003-1879-6396

\section{References}

ABNT, A. B. N. T. (2010). NBR 15895 - Materias pozolânicos - Determinação do teor de hidróxido de cálcio fixado - Método Chapelle modificado (p. 6). p. 6. Rio de Janeiro. 
Cascudo, O., Mendes, M. V. A. S., Carasek, H., and Ferreira, R. B. (2014). Eficiência dos concretos contendo adições minerais frente à ação de cloretos. $1^{\circ}$ Encontro Luso-Brasileiro de Degradação Em Estruturas de Concreto Armado, 1, 1-16. Salvador: Universidade Federal da Bahia - UFBA.

Ferreira, R. B., Pereira, A. C., Lopes, A. N. M., Carasek, H., and Cascudo, O. (2004). Monitoring corrosion and determining of the gravimetric corrosion rate of concretes with high and low reactivity additions subject to chloride action. International RILEM Conference: Use of Recycled Materials in Buildings and Structures, Vol. 2, pp. 700-710. Barcelona.

Figueiredo, C. P., Santos, F. B., Cascudo, O., Carasek, H., Cachim, P., and Velosa, A. (2014). The role of metakaolin in the protection of concrete against the deleterious action of chlorides. RIEM - IBRACON Structures and Materials Journal, 7(4), 685-708.

Friedel, G. (1897). Sur un chloro-aluminate de calcium hydraté se maclant par compression. Bulletin de La Société Française de Minéralogie, 122-136.

Khatib, J. M., Baalbaki, O., and ElKordi, A. A. (2018). Metakaolin. In Waste and Supplementary Cementitious Materials in Concrete (pp. 493-511). https://doi.org/10.1016/B978-0-08-102156-9.00015-8

Luping, T., and Nilsson, L. O. (1993). Rapid Determination of the Chloride Diffusivity in Concrete by Applying an Electric Field. ACI Materials Journal, 89(1), 40-53. https://doi.org/10.14359/1244

Murat, M., and Comel, C. (1983). Hydration reaction and hardening of calcined clays and related minerals III. Influence of calcination process of kaolinite on mechanical strengths of hardened metakaolinite. Cement and Concrete Research, 13(5), 631-637. https://doi.org/http://dx.doi.org/10.1016/0008-8846(83)90052-2

Nilsson, L.-O., Ngo, M. H., and Gjørv, O. E. (1998). High-performance repair materials for concrete structures in the port of Gothenburg. 2th INTERNATIONAL CONFERENCE ON CONCRETE UNDER SEVERE CONDITIONS - ENVIRONMENT and LOADING, Vol. 2, pp. 1193-1198. E and FN Spon.

Nordtest. (1999). Concrete, mortar and cement-based repair materials: Chloride migration coefficient from nonsteady-state migration experiments (NT BUILD 492). p. 8. Espoo.

Oliveira, A. M. de, and Cascudo, O. (2018). Effect of mineral additions incorporated in concrete on

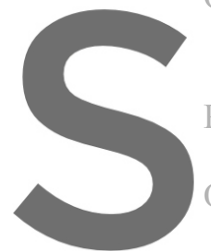
thermodynamic and ki Building Materials,

Pereira, A. C., Lopes, A. of carbonated concre te

Quarcioni, V.A., Chotoli, F. methods for the determ
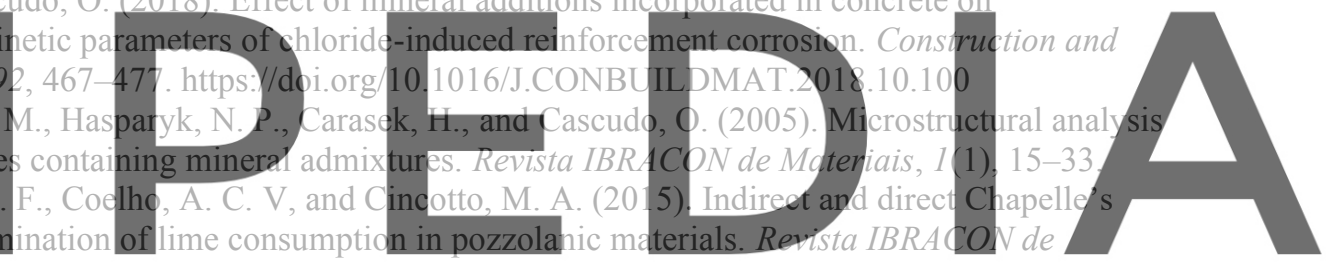
Estruturas e Materiais, 8(1), 1-7. https://doi.org/10.1590/s1983-41952015000100002

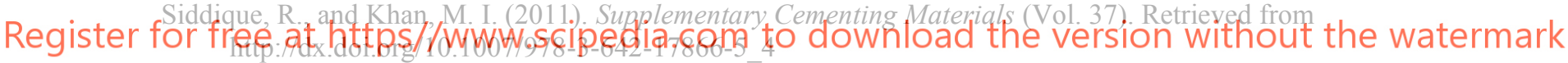

Talero, R. (2012). Synergic effect of Friedel's salt from pozzolan and from OPC co-precipitating in a chloride solution. Construction and Building Materials, 33, 164-180. https://doi.org/http://dx.doi.org/10.1016/j.conbuildmat.2011.12.040 